\title{
A AIDS de nossos dias: quem é o responsável?
}

\author{
Vilma Cardoso Regato \\ Universidade Estácio de Sá \\ Eveline Maria Leal Assmar \\ Universidade Gama Filho
}

\begin{abstract}
Resumo
Investiga-se a problemática da AIDS, com apoio na teoria das perspectivas divergentes (Jones \& Nisbett, 1972) e na crença no mundo justo (Lerner, 1975). Pretende-se demonstrar que a interpretação desse evento vitimador pode variar ao se considerar a pessoa infectada (o ator, que adota causas externas) ou o médico (o observador, que usa causas internas ao ator); que atores e observadores diferem quanto à crença no mundo justo; e que as respostas de combate à doença dependem da atribuição feita pelos pacientes. Participaram da pesquisa 191 portadores de HIV/AIDS e 200 médicos, que responderam ao questionário de atribuição de causalidade e à escala de crença no mundo justo. Os resultados evidenciaram diferenças nas atribuições de atores e observadores nas direções preconizadas e o importante papel mediador da atividade atributiva no enfrentamento do infortúnio. Discute-se a utilidade dos achados para a prática dos profissionais de saúde que lidam com os soropositivos.
\end{abstract}

Palavras-chave: AIDS; atribuição de causalidade; crença no mundo justo; resposta de combate; responsabilidade pessoal

\begin{abstract}
The AIDS of our days: who is responsible? The problem of AIDS is investigated with the support on the theory of divergent perspectives (Jones \& Nisbett, 1972) and the belief in a just world (Lerner, 1975). It is intended to demonstrate that the interpretation of this victimizing event may vary when considering the infected person (the actor, who adopts outside causes) or the doctor (the observer, who uses internal causes to the actor); that actors and observers differ as to the belief in a just world; and that the coping responses to the disease depend on the attribution made by the patients. 191 HIV/AIDS patients and 200 doctors participated in the research, answering the questionnaire on causal attribution and the belief in a just world scale. The results put in evidence differences in the attribution of actors and observers in the expected directions and the important mediating role of the attributive activity in facing the affliction. The usefulness of these findings to a better understanding of the patients' reactions to the disease and to the treatment itself is discussed.
\end{abstract}

Key words: AIDS; causal attribution; belief in a just world; coping responses; personal responsibility

$\mathrm{H}$ á aproximadamente 20 anos convivemos com a AIDS. Em 1981, vieram dos Estados Unidos as primeiras notícias sobre jovens, principalmente do sexo masculino, que morriam em decorrência da combinação de cânceres raros com pneumonias. Pouco se sabia sobre este novo quadro, além de ser comum em homossexuais, usuários de drogas injetáveis ou pessoas com distúrbios imunológicos induzidos por transplantes.

Com o passar do tempo, muito se descobriu sobre a AIDS. Hoje já não se fala em grupos, mas, sim, em fatores de risco da infecção pelo HIV, o que torna toda pessoa potencialmente vulnerável à sua aquisição. Como nova entidade clínica, a infecção pelo HIV não parou de crescer, sendo fartamente divulgada pela Organização Mundial de Saúde que, nos últimos 50 anos, não houve epidemia mais grave do que a AIDS, o que lhe conferiu status de pandemia. No Brasil, são alarmantes as estatísticas sobre sua progressão, fazendo-a ocupar uma posição que oscila entre o terceiro e o quarto lugar na distribuição dos casos notificados mundialmente (Ramos, Hinrichsen, Corrêa, Sá, \& Toscano, 1997).

A AIDS, quando diagnosticada, assola seu portador de dúvidas e certezas. Dúvidas a respeito de desenvolvê-la ou não (embora a maioria das pessoas infectadas pelo HIV a desenvolva) e do quão doloroso e inevitável poderá ser seu progresso, fazendo-o conviver permanentemente com a certeza de morte breve. Por sua associação inicial com comportamentos socialmente desviantes - e, por isso mesmo, sujeitos à condenação implacável da sociedade - a aquisição do vírus trouxe ainda para seus portadores o problema adicional de tornar pública sua condição de infectado. Segundo Lent e 
Valle (1997), o medo do julgamento e da exclusão social desencorajava a declaração de responsabilidade pessoal pela ocorrência do infortúnio, criando o portador clandestino. $\mathrm{Na}$ condição de clandestinidade, pelo menos por algum tempo, o portador não sofria perdas, seja do parceiro afetivo, do emprego, dos amigos, seja da família. Após duas décadas, se é fato que houve avanços significativos no tratamento da AIDS, pouca coisa mudou do ponto de vista do preconceito e da discriminação, até mesmo quando se trata de crianças infectadas pelo vírus.

É notório que os julgamentos das pessoas sobre o que acontece a si mesmas e aos outros, bem como sobre as circunstâncias e condutas que o provocam, assumem um papel de especial relevância em suas relações com a vida e com as demais pessoas que as cercam. Tais julgamentos costumam ser desferidos principalmente diante de eventos inesperados e negativos, na tentativa de entender o porquê de sua ocorrência. Talvez a primeira pergunta que nos ocorra seja: “quem é o responsável?”.

Questões sobre as causas dos eventos e a responsabilidade por sua ocorrência constituem o foco de interesse da teoria psicossocial de atribuição de causalidade cujos pressupostos básicos dizem respeito à necessidade que as pessoas têm de compreender as origens de suas experiências e de buscar explicações para os eventos que lhes ocorrem ou que observam em seu dia-a-dia. Esta tendência natural de conhecer as causas dos acontecimentos é uma tentativa do homem de exercer um controle ilusório sobre o mundo que o cerca, tornando-o mais estável e previsível (Heider, 1958/1970).

De acordo com Heider (1958/1970), causalidade pessoal (interna) e causalidade impessoal (externa) constituem as duas formas básicas de atribuição causal aos eventos. A primeira reside nas próprias intenções da pessoa e estão sob seu controle; a segunda decorre de forças externas à pessoa, de forças do ambiente, e, portanto, fora de seu controle. Assim, por exemplo, seria mais provável atribuirmos causalidade pessoal a um portador de HIV que o tenha adquirido por via sexual, e causalidade impessoal a um outro, que tenha contraído o vírus numa transfusão de sangue.

Ainda que Heider (1958/1970), em suas proposições originais, tivesse chamado a atenção para a possível distinção entre os processos atributivos de quem pratica a ação e de quem a observa, deve-se a Jones e Nisbett (1972) a sistematização desses princípios através da teoria das perspectivas divergentes. Segundo esses autores, a explicação causal de um fenômeno qualquer pode variar de acordo com a perspectiva de quem o julga. Assim, o agente da ação (o ator), quando avalia os efeitos de seus comportamentos, principalmente se eles forem negativos, tende a enfatizar o meio ambiente na indução e causação dos mesmos, atribuindo-lhes causas externas e, logo, isentando-se da responsabilidade pessoal por sua ocorrência. Ao julgar, porém, a ação do outro (na condição de observador), estando fora do ambiente de sua causação, é mais propenso a enfatizar disposições pessoais estáveis do ator, atribuindo-lhe, portanto, causas internas ao próprio ator. Desse modo, o observador responsabili- za o ator pela ocorrência do comportamento observado, culpabilizando-o por seus efeitos.

Com base nessas proposições, e tomando a AIDS como foco de análise, podemos supor, então, que os soropositivos tenderiam a fazer mais atribuições externas à aquisição do vírus HIV, responsabilizando por seu infortúnio ora os parceiros, ora o destino e, ainda, a falta de campanhas preventivas. Em contrapartida, os soronegativos, ao julgar um portador do vírus, tenderiam a atribuir às suas características pessoais ou comportamentos anteriores a causa de seu problema atual, responsabilizando-o pela situação. Afinal, uso de drogas, homossexualismo e promiscuidade sexual, além de não fazerem parte da norma social, são percebidos pelos observadores como condições controláveis, o que lhes facilita a imputação de atribuições causais pessoais ou internas aos portadores do HIV (Sheehan, Lennon, \& McDevitt, 1987). Se a causa de uma ação negativa é vista como interna e controlável, sem circunstâncias atenuantes, dessa atribuição resultam julgamentos de responsabilidade pessoal ao indivíduo que a praticou (Weiner, 1986, 1995).

Estudos realizados no Brasil por Iório (1996) e Iório, Ferreira e Regato (1996), com pacientes infectados pelo vírus, trouxeram evidências em favor das proposições relacionadas ao efeito ator-observador. Em ambos os casos, portadores de HIV e pessoas sadias fizeram atribuições diferenciadas à aquisição do HIV, com os primeiros responsabilizando o destino ou a desonestidade de parceiros já infectados que não evitaram disseminar o vírus, e as últimas culpabilizando as próprias vítimas por seu infortúnio, sobretudo por sua opção homossexual.

Alguns achados específicos, no entanto, levaram-nos a cogitar de novas questões em busca de um alargamento da compreensão do problema da AIDS e do próprio viés atorobservador. No trabalho de Iório (1996), por exemplo, foi demonstrado que observadores homossexuais fazem também atribuições causais externas, à semelhança dos próprios pacientes, prevalecendo, nesse caso, a chamada atribuição defensiva (Shaver, 1970, 1985), e não mais o viés do observador, o que pode ser explicado como uma forma de tentarem se proteger da idéia de que esses efeitos negativos possam lhes atingir no futuro. Daí se depreende que determinados tipos de observadores podem fugir à predição geral da abordagem das perspectivas divergentes, o que nos levou a questionar se os julgamentos dos médicos, com percepção informada do problema da AIDS e de sua etiologia, seriam equivalentes aos das pessoas leigas. Nesse sentido, formulamos a seguinte hipótese de pesquisa:

(Hipótese 1) Os portadores de HIV/AIDS (os atores) tendem a fazer atribuições mais externas para explicarem a aquisição do vírus da imunodeficiência, ao passo que os médicos (os observadores) tendem a fazer atribuições mais internas aos pacientes de HIV/AIDS.

Por outro lado, no estudo de Iório e colaboradores (1996), observamos, ainda que de forma não sistemática, o quanto os soropositivos homossexuais, ainda não debilita- 
dos pelo HIV, negaram a doença, diferentemente dos pacientes em que já se manifestavam os sintomas da AIDS. Como, porém, nesse trabalho, não havia a preocupação de comparar a atividade atributiva de portadores com diferentes graus de infecção, não nos foi possível avaliar empiricamente se os pacientes assintomáticos fariam mais atribuições externas que os sintomáticos. Adicionalmente, como todos os pacientes estudados tinham sido infectados por uma única via de contágio (relações homossexuais), perguntamo-nos se as atribuições à AIDS seguiriam os mesmos padrões em portadores infectados por outras vias, como, por exemplo, em heterossexuais. Como afirmam Parker, Bastos, Galvão e Pedrosa (1994), os soropositivos homossexuais, além da divergência prevista por estarem na pele de "atores do problema”, ainda são vistos como “doentes-padrão para a síndrome da imunodeficiência” (p. 31), e os efeitos desta estigmatização, muitas vezes, acabam recaindo sobre eles mesmos pela introjeção do estigma, que os faz sentir mais culpa pela contração do HIV do que os heterossexuais infectados.

Em se tratando, porém, de profissionais de saúde como os médicos, com conhecimento especializado, poderíamos supor que suas atribuições não sofreriam variações em função da origem e gravidade da doença, continuando a ser internas aos pacientes, diferentemente das pessoas leigas, que, ao julgarem os soropositivos, tendem a atribuir mais responsabilidade e culpa aos portadores de HIV homossexuais do que aos heterossexuais (Anderson, 1992), mas, ao julgarem seu próprio infortúnio, tendem a se deixar levar pelo maior ou menor grau com que os sintomas da doença já se manifestem (Iório et al., 1996). Tomando por base essas considerações, formulamos duas hipóteses específicas:

(Hipótese 2) Há diferenças significativas entre os atores quanto ao tipo de atribuição à AIDS em função das diferentes vias de contágio do vírus HIV e das fases distintas da infecção, com os homossexuais fazendo mais atribuições internas do que os heterossexuais e os assintomáticos fazendo mais atribuições externas do que os sintomáticos;

(Hipótese 3) Não há diferenças significativas entre os tipos de atribuição dos observadores médicos à AIDS, em função das diferentes vias de contágio e das fases distintas da infecção pelo HIV.

Mais do que uma mera atividade cognitiva de exploração e interpretação do ambiente social, as atribuições causais aos eventos estressores da vida diária são postas em especial relevo por seu papel mediador entre os estímulos do meio e os comportamentos subseqüentes. Nesse sentido, as explicações causais constituem mecanismos extremamente úteis para o entendimento das respostas de combate (coping responses) de que os indivíduos lançam mão para enfrentar os infortúnios (Aronson, Wilson, \& Akert, 1997; Bernstein, Roy, \& Wickens, 1997; Dela Coleta, 1980; Flaskerud, 1992).

Flaskerud (1992) e Weiss (1997) comentam que, no caso específico da AIDS, o estudo das estratégias de coping reveste-se de particular importância por seus aspectos de incurabilidade e letalidade, que podem levar os doentes a uma grande resistência em relação ao tratamento. Não obstante essas resistências, observam-se estilos variados de resposta à doença e à situação pessoal gerada pela vitimação. De um lado, há os que continuam a ser produtivos no trabalho, os que lutam por se manter sadios com o uso das terapias combinadas, os que fazem militância, os que se expõem ao julgamento inclemente da sociedade, etc. De outro, deparamonos com aqueles que se escondem, abandonam suas atividades, mantêm-se na clandestinidade, desistindo, às vezes, até do próprio tratamento.

Admitindo-se aqui a ação moderadora da atividade atributiva na interpretação da ocorrência da AIDS, poderíamos especular em torno de dois tipos de situação. Em primeiro lugar, os infectados pelo HIV que fizessem atribuição interna em relação à contração do vírus tenderiam a exibir repostas de combate positivas à doença no sentido de engajar-se no próprio tratamento, eliminar comportamentos de risco e, assim, evitar a proliferação do vírus, condutas essas que lhes assegurariam, pelo menos, a manutenção de sua auto-estima e uma forma de tentar "redimir-se" em relação à fonte de vitimação. A busca de equilíbrio entre ações e cognições dos infectados que se responsabilizassem pela contração do HIV poderia justificar, inclusive, a ação de soropositivos militantes na luta contra a AIDS.

Em segundo lugar, os portadores de HIV que fizessem atribuições externas à contaminação, eximindo-se da responsabilidade pessoal por sua ocorrência, não vivenciariam, provavelmente, o sentimento de culpa em relação à doença adquirida. Em contrapartida, porém, tenderiam a negar a infecção a ponto de não evitar sua disseminação e de não buscar, já em fase inicial de diagnóstico, os tratamentos oferecidos pelas redes de saúde. Em suma, os pacientes que se percebessem como vítimas de parceiros e/ou de circunstâncias, não se veriam capacitados a promover mudanças que os reequilibrassem, deixando ao meio externo o encargo de viabilizar as condições para a recuperação de seu bem-estar, ou, pelo menos, o abrandamento dos efeitos do problema que os acomete.

O bom enfrentamento dos doentes às enfermidades não só facilita o trabalho dos médicos, como também os debilita menos (se considerarmos os efeitos maléficos, cientificamente comprovados, da depressão no sistema imunitário). Já a resposta de combate negativa ao infortúnio só consegue agravar o que já é terrivelmente penoso para os próprios portadores e para todos os que lidam direta ou indiretamente com eles (Moulton, Sweet, Temoshok, \& Mandel, 1987; Santrock, 1997). A quarta hipótese da pesquisa sintetiza essa relação:

(Hipótese 4) Atores que apresentam tipo atribuicional interno ao próprio contágio pelo vírus HIV tendem a apresentar respostas de combate mais positivas em relação à doença do que atores que realizam atribuição externa, que apresentam respostas de combate mais negativas.

Uma outra abordagem importante na atribuição a eventos acidentais é a hipótese do mundo justo, de Lerner (1991), 
segundo a qual as pessoas desenvolvem a crença de que todos têm o que merecem ou merecem o que têm. Como sabemos, há condições situacionais (do ambiente) e disposicionais (da pessoa) influenciando, significativamente, o processo atributivo. De acordo com Lerner, quando os fenômenos são causados por fatores aparentemente acidentais, torna-se muito confuso para o observador atribuir-lhes uma causa. A própria idéia de acidente conota a ocorrência de fatos imprevistos e incontroláveis, o que confronta o homem com o sentimento de impotência e a falta de controle, deixando-o à mercê das forças do imponderável.

Para justificar a ocorrência de fatos dessa natureza, é que o homem desenvolve a crença de que bons eventos acontecem a boa gente (os cumpridores das normas sociais, por exemplo) e maus eventos, a pessoas ruins (todos os que infringem as normas sociais). Assim, acreditar no mundo justo é tirar das ocorrências imprevistas seu caráter de aleatoriedade (Lerner, 1975). Uma outra função adaptativa da crença no mundo justo é ressaltada por Furnhan e Procter (1989) na medida em que, segundo eles, ela também atende ao desejo do ser humano de tornar o mundo a sua volta estável e previsível.

Em estudo realizado por O’Donnel, Pleck, Snarey e Rose (1987, citados por Anderson, 1992), com 237 profissionais de saúde, foi verificado que $10 \%$ deles declararam concordar com a afirmação de que "a AIDS é a punição de Deus para a imoralidade”. Os próprios resultados obtidos por Anderson (1992), já aludidos anteriormente, seguem essa mesma direção, de vez que os sujeitos, que culpabilizaram mais o homossexual do que o heterossexual pela aquisição do HIV, justificaram seus julgamentos afirmando ser a AIDS uma punição de Deus àqueles que vivem uma orientação sexual distinta da socialmente prescrita.

Articulando-se as predições da atribuição diferencial de causalidade à hipótese de Lerner (1975, 1991), poderíamos supor, então, que atores e observadores difeririam em relação à crença do mundo justo? E ainda, que os tipos de atribuição interna e externa variariam em função do grau com que os pacientes e os médicos acreditam que o mundo é justo? Essas indagações estão contidas nas hipóteses cinco e seis da presente pesquisa:

(Hipótese 5) Os portadores de HIV/AIDS (atores) tendem a possuir maior crença no mundo injusto ao passo que os observadores tendem a possuir maior crença no mundo justo; e

(Hipótese 6) Atores e observadores que fazem atribuições internas à AIDS, apresentam maior crença no mundo justo, enquanto os que fazem atribuições externas apresentam maior crença no mundo injusto.

Nosso interesse em estudar as vítimas do HIV/AIDS justifica-se não só pelo fato de os índices de contaminação estarem se ampliando por todos os segmentos sociais, como também pela existência de muito poucos estudos brasileiros, com os próprios pacientes e com profissionais de saúde, que se preocupem em analisar a relação entre a interpretação das causas da doença e as formas de lutar contra ela. Acreditamos que informações dessa natureza possam orientar futuras estratégias de atendimento psicológico aos soropositivos e, até mesmo, programas de saúde pública, visando a informação da sociedade como um todo e o próprio controle da proliferação da AIDS.

\section{Método}

\section{Participantes}

A pesquisa foi efetuada em uma amostra total de 391 indivíduos do sexo masculino, entre 18 e 50 anos, sendo 191 atores (portadores de HIV) e 200 observadores (médicos). Os médicos foram entrevistados nos próprios hospitais do Rio de Janeiro em que trabalhavam e os pacientes, também nesses mesmos hospitais, antes ou depois do tratamento ambulatorial a que estavam sendo submetidos, ou enquanto atuavam como voluntários do Grupo Pela Vidda-Rio.

Os soropositivos foram divididos em 4 grupos, conforme a via de contágio sexual (hetero ou homossexual) e o estágio da infecção do HIV (assintomáticos ou sintomáticos). Os médicos foram, igualmente, divididos em 4 grupos, de forma que cada grupo julgasse um dos quatro casos correspondentes aos grupos dos portadores HIV em estudo. Dos oito grupos formados, seis ficaram constituídos de 50 participantes, um, de 46 e o outro, de 45.

\section{Instrumentos}

Para a coleta dos dados, foram utilizados um questionário de atribuições causais à AIDS, adaptado de um outro utilizado por Dela Coleta (1980), e a escala do mundo justo, de Rubin e Peplau (1975), adaptada por Dela Coleta (1980).

O questionário de atribuição de causalidade é apresentado em duas versões - uma para o ator (forma A) e outra para o observador (forma B), com perguntas abertas e fechadas, relativas à atribuição de causalidade e responsabilidade pela ocorrência da vitimação. Na forma A abordava-se diretamente o infortúnio da AIDS, cabendo aos soropositivos responder a questões relacionadas ao seu problema. Na forma $\mathrm{B}$, relatava-se o caso de um portador de HIV/AIDS que havia adquirido o vírus por uma de duas vias de contágio (homossexual e heterossexual), estando em fases distintas da infecção (sintomática e assintomática). Havia, portanto, quatro estórias distintas, correspondentes à situação dos quatro grupos de portadores, seguidas de perguntas semelhantes às dos atores.

O instrumento utilizado para medir a crença no mundo justo é composto de 15 itens (em vez dos 20 itens originais), apresentados em formato Likert de seis pontos, variando de 1 (concordo totalmente) a 6 (discordo totalmente). Os dados obtidos foram submetidos à análise fatorial de componentes principais, com rotação Varimax, da qual resultaram dois fatores interpretáveis, que explicaram 44,30\% da variância total do instrumento. Em ambos os fatores, foram retidos os itens com cargas fatoriais iguais ou superiores a 0,30, congruência semântica com os demais itens do fator e correlação itemtotal igual ou superior a 0,20. O primeiro fator compôs-se de nove itens, que denotam crenças em um mundo justo e o 
segundo fator, de seis itens, que representam crenças de injustiça em relação às ocorrências vividas ou observadas pelas pessoas.

\section{Resultados}

Como, de um modo geral, as perguntas que abordavam a atribuição de causa e responsabilidade pela contração do HIV eram perguntas abertas, as respostas dos entrevistados foram submetidas à análise de conteúdo para efeito de sua classificação no sistema de categorias, proposto por Dela Coleta (1980), mas modificado neste trabalho por conta das especificidades da temática e dos próprios participantes do estudo. A categorização levou em conta a necessidade de identificar os fatores disposicionais (pessoais) e situacionais (ambientais), direta ou indiretamente envolvidos com a infecção contraída, tal como percebidos pelos pacientes e médicos.

No que se refere à atribuição das causas responsáveis pelo infortúnio (Tabela 1), as respostas dos atores e observadores foram classificadas em quatro categorias: (a) causas internas - referentes aos próprios atores, seus atributos ou a seus comportamentos anteriores, como, por exemplo, promiscuidade e não-uso de preservativos; (b) causas externas - localizadas fora dos portadores de HIV e relacionadas a outras pessoas ou entidades, como a infidelidade do parceiro, a não-revelação da soropositividade por parte do mesmo, a falta de campanhas de esclarecimento, o destino; (c) causas divididas entre ator e ambiente - localizadas dentro e fora do portador de HIV (no parceiro, por exemplo), como confiança excessiva no parceiro cujos atos e atitudes demonstravam ser dispensável o uso de preservativos) e (d) ausência de resposta - recusa, omissão ou impropriedade da resposta.

Como podemos observar, os atores, em boa parte $(46,60 \%)$, tenderam a isentar-se da responsabilidade pela contração do vírus, creditando ao ambiente - seja na pessoa do parceiro, seja nas autoridades de saúde pública, que não divulgam campanhas informativas para a prevenção da população - a origem de seu contágio. Um dado curioso, mas sugestivo, é que o segundo percentual mais alto obtido nesse mesmo grupo se situa na categoria de recusa ou omissão de resposta (22,51\%), o que pode também ser interpretado como uma tentativa de esquivar-se do problema. Nas demais categorias - auto-atribuição e divisão de responsabilidade - que denotam a consciência de que seus próprios comportamen-

Tabela 1

Atribuição causal à contaminação por HIV

\begin{tabular}{lcrrr}
\hline \multirow{2}{*}{ Categorias } & \multicolumn{2}{c}{ Atores } & \multicolumn{2}{c}{ Observadores } \\
\cline { 2 - 5 } & $\mathrm{f}$ & \multicolumn{1}{c}{$\%$} & \multicolumn{1}{c}{$\mathrm{f}$} & \multicolumn{1}{c}{$\%$} \\
\hline Causas internas ao ator & 34 & 17,80 & 161 & 80,50 \\
Causas externas ao ator & 89 & 46,60 & 8 & 4,00 \\
Causas divididas & 25 & 13,09 & 21 & 10,50 \\
Não responderam & 43 & 22,51 & 10 & 5,00 \\
\hline \multicolumn{1}{c}{ Total } & 191 & 100,00 & 200 & 100,00 \\
\hline
\end{tabular}

tos anteriores podem ter concorrido para sua vitimação - os percentuais foram relativamente próximos entre si, mas distantes das tendências de negação de responsabilidade.

Quando se trata dos observadores, o panorama apresenta-se bastante modificado na medida em que os médicos responsabilizaram maciçamente os soropositivos por seu infortúnio (80,50\%). A segunda maior incidência de respostas desse grupo, mas com um percentual bastante reduzido, refere-se à divisão de responsabilidade entre vítima e parceiro pela aquisição da AIDS (10,50\%). As demais categorias não têm expressividade numérica, já que 91\% das respostas dos médicos concentraram-se nas categorias que, de forma direta ou indireta, atribuem responsabilidade aos próprios doentes.

A comparação dos resultados obtidos nesses dois grupos, para efeito de comprovação empírica do viés ator/ observador, indicou diferenças significativas no tipo de atribuição entre pacientes e médicos, com os primeiros fazendo mais atribuições externas e os últimos, mais atribuições internas aos atores $\left(\chi^{2}=20,142 ; p<0,001\right)$, corroborando-se, portanto, a hipótese H-1.

A verificação de “quem foi o responsável” pela aquisição do HIV foi também realizada através da obtenção de dados sobre a importância que atores e observadores atribuíam a quatro tipos de fatores que poderiam ter contribuído para a contração do HIV (1 para o mais importante e 4 para o menos importante), quais sejam: outras pessoas; eu/ele mesmo; situação/lugar em que vivia; e acaso, azar ou destino (Tabela 2).

Tabela 2

Ordenações médias ${ }^{\mathrm{a}}$ dos fatores responsáveis pela aquisição do HIV

\begin{tabular}{lcc}
\hline \multicolumn{1}{c}{ Fatores } & Atores & Observadores \\
\hline Outras pessoas & 1,91 & 2,34 \\
Eu/ele mesmo & 2,29 & 1,39 \\
Situação/lugar em que vivia & 2,59 & 2,57 \\
O acaso (azar/destino) & 3,10 & 3,68 \\
\hline \multirow{2}{*}{ a Quanto menor a média, maior a importância do fator. }
\end{tabular}

Como podemos constatar, os atores indicaram o item “outras pessoas” - o(s) parceiro(s), por exemplo - como o que mais contribuiu para o seu infortúnio, ratificando a tendência de atribuição causal externa para explicarem a aquisição do HIV. Os observadores, de igual modo, reafirmaram sua propensão para julgamentos de responsabilidade pessoal dos portadores de HIV por sua contaminação, recorrendo, mais uma vez, a características disposicionais dos atores para justificar seus problemas. A comparação das respostas dos dois grupos, re-agrupadas segundo o tipo de atribuição interna (eu/ele mesmo) ou externa (outros, situação/lugar em que vivia e acaso), revelou a existência de diferenças significativas entre os dois grupos, com os médicos enfatizando mais fatores internos aos atores do que eles mesmos ( $M=1,29$ versus $M=2,29 ; t=9,61 ; p<0,001)$ e os atores, comparativamente 
aos médicos, valorizando mais fatores externos $(M=2,53$ versus $M=2,86 ; t=7,79 ; p<0,001)$. Tais resultados reforçam, portanto, a predição geral da hipótese $\mathrm{H}-1$ de que a atribuição de causalidade à AIDS depende da perspectiva de quem julga.

Com o intuito de verificarmos se havia diferenças atribuicionais significativas entre os grupos de atores (hipótese $\mathrm{H}-2$ ) e de observadores (hipótese $\mathrm{H}-3$ ), motivadas pelas vias de contágio - homossexual e heterossexual - e por fases distintas da infecção pelo HIV - sintomáticos e assintomáticos - confrontamos as freqüências obtidas nas categorias de causas internas e de causas externas, apresentadas na Tabela 1 e de maior relevância neste estudo, comparando os diferentes grupos, dois a dois (Tabela 3).

Tabela 3

Comparações entre subgrupos ${ }^{\mathrm{a}}$ de atores quanto às atribuições causais internas e externas usadas para explicar a aquisição do HIV

\begin{tabular}{lcc}
\hline \multicolumn{1}{c}{ Subgrupos } & $\chi^{2}$ & Significância \\
\hline A.SHT X A.AHT & $6,75^{*}$ & $p<0,005$ \\
A.SHT X A.SHM & 0,21 & n. s. \\
A.SHM X A.AHM & 0,08 & n. s. \\
A.AHT X A.AHM & $15,88^{* *}$ & $p<0,001$ \\
\hline
\end{tabular}

${ }^{a}$ A.SHT: portadores de HIV heterossexuais / A.AHT: portadores de AIDS heterossexuais A.SHM: portadores de HIV homossexuais / A.AHM: portadores de AIDS homossexuais

A inspeção à tabela revela a existência de diferenças significativas em apenas duas comparações, mas na direção contrária à esperada, não sendo, portanto, corroborada a hipótese $\mathrm{H}-2$ : atores heterossexuais assintomáticos recorreram mais a causas internas que os sintomáticos e atores sintomáticos heterossexuais adotaram mais causas internas que os homossexuais.

Quanto aos médicos, tal como o previsto na hipótese $\mathrm{H}-3$, as informações referentes à orientação sexual dos pacientes (via de contágio) e a fase da infecção não produziram efeitos diferenciais em suas atribuições à aquisição da síndrome da AIDS por parte dos atores. A própria severidade da patologia parece constituir, por si só, condição suficiente para o uso de causas explicativas de natureza disposicional e o julgamento de responsabilidade pessoal dos pacientes por seu infortúnio (Tabela 4).

Para avaliar a relação entre atribuições causais e estratégias de combate à soropositividade por parte dos pacientes, os dados referentes aos atores foram submetidos à análise de conteúdo para a identificação das categorias de resposta mais freqüentemente reportadas (Tabela 5).

Algumas tendências principais podem ser observadas: (a) prevalência de respostas de combate negativas (55\%), sendo ressaltados, entre outros, sentimentos de finitude, desmotivação para o trabalho e o próprio tratamento, desejo de isolamento por medo de rejeição; (b) respostas de comba-
Tabela 4

Comparações entre subgrupos ${ }^{\mathrm{a}}$ de observadores quanto às atribuições causais internas e externas usadas para explicar a Aquisição do HIV

\begin{tabular}{lcc}
\hline \multicolumn{1}{c}{ Subgrupos } & $\chi^{2}$ & Significância \\
\hline O.ASHT x O.AAHT & 0,50 & n. s. \\
O.ASHM x O.AAHM & 0,01 & n.s. \\
O.ASHM x O.AAHM & 2,48 & n. s. \\
O.AAHT x O.AAHM & 0,71 & n. s. \\
\hline
\end{tabular}

${ }^{a}$ O.ASHT: médicos julgando portadores de HIV heterossexuais O.AAHT: médicos julgando portadores de AIDS heterossexuais O.ASHM: médicos julgando portadores de HIV homossexuais

O.AAHM: médicos julgando portadores de AIDS homossexuais

Tabela 5

Respostas de combate à AIDS - atores

\begin{tabular}{lrc}
\hline \multicolumn{1}{c}{ Categorias } & \multicolumn{1}{c}{ f } & \multicolumn{1}{c}{$\%$} \\
\hline Respostas de combate positivas & 52 & 27,23 \\
Respostas de combate negativas & 105 & 54,97 \\
Respostas de combate ambivalentes & 31 & 16,23 \\
Não responderam & 3 & 1,57 \\
\hline Total & 191 & 100,00 \\
\hline
\end{tabular}

te positivas (27\%) relativas a mudanças de conduta pós-contágio para controle da proliferação do HIV e da própria infecção, militância, responsabilidade sobre o próprio tratamento, etc.; (c) respostas de combate ambivalentes (16\%), em que se mesclaram reações negativas e positivas à soropositividade.

A comparação entre os tipos de atribuição e as respostas de combate positivas e negativas trouxe evidências significativas $\left(\chi^{2}=4,75 ; p<0,05\right)$ em favor da relação entre o modo como o portador de HIV interpreta as origens de seu problema e as estratégias desenvolvidas para enfrentar a doença e suas conseqüências.

A previsão de que portadores de HIV e médicos difeririam quanto às crenças de justiça no mundo (hipótese $\mathrm{H}-5$ ) foi evidenciada, conforme podemos atestar no exame da Tabela 6 , com os atores percebendo o mundo como mais injusto e os médicos, como mais justo.

No que diz respeito à hipótese $\mathrm{H}-6$, na qual se preconizava uma correlação positiva significativa entre a crença no mundo justo e o padrão atributivo à AIDS, a comparação das médias (Tabela 7) propiciou apoio empírico para essa predição, já que os portadores de HIV que atribuíram a responsabilidade da contaminação a causas externas demonstraram maior crença no mundo injusto, e os que buscaram causas internas revelaram maior crença no mundo justo.

\section{Discussão e Conclusões}

Os objetivos do presente trabalho foram, em primeiro lugar, testar se as predições teóricas, de Jones e Nisbett (1972), 
Tabela 6

Comparações ${ }^{\mathrm{a}}$ entre atores e observadores quanto às crenças no mundo justo

\begin{tabular}{lrcrc}
\hline \multirow{2}{*}{ Dimensões } & \multicolumn{2}{c}{ Médias } & \multirow{2}{*}{$t$} & $p$ \\
\cline { 2 - 3 } & Atores & Observadores & & \\
\hline Mundo justo & 37,30 & 31,08 & 9,36 & $<0,001$ \\
Mundo injusto & 15,86 & 18,81 & $-5,91$ & $<0,001$ \\
\hline
\end{tabular}

${ }^{1}$ Quanto menor a média, maior a crença no mundo justo

Tabela 7

Comparações ${ }^{\mathrm{a}}$ entre atribuição interna/externa e crenças em um mundo justo/injusto ${ }^{\mathrm{b}}$

\begin{tabular}{lcccc}
\hline \multicolumn{1}{c}{ Dimensões } & $\begin{array}{c}\text { Causas } \\
\text { internas }\end{array}$ & $\begin{array}{c}\text { Causas } \\
\text { externas }\end{array}$ & $t$ & $p$ \\
\hline Mundo justo & 32,10 & 37,46 & $-6,18$ & $<0,001$ \\
Mundo injusto & 18,54 & 16,28 & $-3,72$ & $<0,001$ \\
\hline
\end{tabular}

${ }^{a}$ Quanto menor a média, maior a crença

${ }^{\mathrm{b}}$ Referente à amostra total

sobre atribuição diferencial de causalidade se aplicariam a portadores de HIV/AIDS (os atores) e médicos (os observadores) ao explicarem a aquisição da doença, bem como avaliar se a via de contágio e a fase da infecção afetariam essas explicações causais. Em segundo lugar, verificar a correspondência entre as atribuições dos atores e suas respostas de combate ao infortúnio vivido, e, finalmente, verificar se atores e observadores apresentariam diferenças em suas crenças de um mundo justo em face da vivência real ou imaginada da AIDS e, ainda, se essas crenças estariam articuladas ao tipo de atribuição causal.

As evidências empíricas em favor da predição geral da teoria das perspectivas divergentes (hipótese $\mathrm{H}-1$ ) demonstram que atores diferem de observadores médicos na explicação do contágio, com os primeiros justificando a condição da soropositividade por causas situacionais e não pessoais, e os últimos, inversamente, recorrendo a causas disposicionais, internas aos atores. Daí se depreende que enquanto os portadores do HIV se isentam da responsabilidade por sua vitimação, os médicos responsabilizam-nos diretamente por seu infortúnio, tendências essas consistentes em uns e outros grupos. Acreditamos que, atualmente, diante da intensa mobilização dos meios de comunicação de massa, com a veiculação de campanhas informativas para prevenção do risco de contaminação, as pessoas portadoras ou não do HIV já tomaram consciência de que é possível não correr riscos. No caso dos portadores, no entanto, esse conhecimento objetivo parece não ser suficiente para que se percebam como responsáveis pelo problema que os acometeu, o que suscita dúvidas quanto a seus comportamentos póscontágio, direcionados ao controle da doença.

Jones e Davis (1965) salientam que a tendência dos atores em atribuir causa externa aos efeitos negativos de suas ações deve-se à necessidade da manutenção da auto-estima. Não parece difícil entender o quanto deve ser penoso para o soropositivo responsabilizar-se pela contração de um vírus com as denotações do vírus HIV. O HIV é, no mínimo, o agente etiológico de uma patologia incurável, podendo significar, ainda, prejuízos de ordem afetiva, social, e econômica, além da morte de seus portadores.

Por outro lado, o fato de existirem medidas preventivas ao vírus, que os médicos presumem não terem sido utilizadas pelos portadores analisados, e a percepção informada do problema pelos médicos, fazem, provavelmente, com que eles procedam a uma avaliação mais objetiva da etiologia da doença, havendo pouca margem para julgamentos muito subjetivos ou menos severos. É possível cogitar também que, ao adotarem esse padrão atribuicional, os observadores podem estar exercendo certo controle sobre o evento vitimador, tentando afastar de si mesmos a idéia de um possível contágio (Dela Coleta, 1982).

A constatação, entre os atores, de tendências inversas às esperadas no que se refere a variações nas atribuições causais, motivadas pela via de contágio ou fase da infecção, talvez possa ser creditada ao fato de o maior número de entrevistados heterossexuais e assintomáticos pertencer ao Grupo Vidda-Rio. A atuação em um grupo de militância contra a AIDS pode levar a maior conscientização da responsabilidade pela própria contaminação, justificando-se, então, a predominância entre eles de atribuições internas em relação à síndrome de imunodeficiência (e não de atribuições externas), comparativamente aos homossexuais e aos sintomáticos.

Já os médicos, tal como o esperado, não apresentaram diferenças no tipo atribuicional em função da origem e gravidade da infecção (hipótese $\mathrm{H}-3$ ), o que nos leva a crer que, para eles, a doença, em si mesma, é que constitui a figura em seu campo perceptual e tudo o mais parece ficar em segundo plano. Logo, os atores seriam os responsáveis por uma patologia grave, para a qual existem informação e prevenção, tornando-se, supostamente, a via de contágio e o estado de imunossupressão provocado pelo vírus fatores acessórios, que não lhes cabia considerar na análise do caso.

Em suma, os dados relativos à atividade atributiva dos médicos no caso específico da AIDS confirmam, por um lado, as tendências, observadas em observadores leigos, de adotar, preferencialmente, causas disposicionais para explicar a contração do HIV (Iório, 1996; Iório et al., 1996), mas, por outro lado, contrariam as pressuposições de Anderson (1992) de que a informação a respeito da AIDS poderia modificar suas atribuições internas, tornando-os mais complacentes em seus julgamentos do que as pessoas desinformadas.

As relações observadas nos grupos de atores entre tipo atribuicional interno/respostas de combate positivas e tipo atribuicional externo/respostas de combate negativas (hipótese H-4) constituem subsídios valiosos à compreensão dos diferentes modos pelos quais os pacientes reagem ao tratamento e as repercussões diferenciadas que a consciência da infecção traz para a sua vida. Cumpre salientar, no entanto, que respostas de combate negativas podem estar também associadas a condicionantes culturais, como afirma 
Santrock (1997), uma vez que a AIDS ainda significa rejeição e exclusão social, seguidas de degradação física e morte para seus portadores. Conviver com perspectivas de tal monta, torna compreensível a enorme dificuldade de muitos portadores em lidar com o diagnóstico de soropositividade e responder positivamente a um processo de vitimação tão doloroso.

Entendendo-se, contudo, que o mau enfrentamento da doença acaba por gerar um baixo investimento dos soropositivos no próprio tratamento, devido à provável negação do HIV, parece-nos procedente afirmar que a atribuição interna e julgamentos de responsabilidade pessoal pelo infortúnio poderiam resultar em estratégias mais adequadas à luta contra a síndrome e, provavelmente, viabilizar maior qualidade de vida para eles, guardados, obviamente, os limites que as graves conseqüências da infecção, por si só, trazem aos seus portadores.

Tomando por base os achados de Aronson, Wilson e Akert (1997) e Santrock (1997), segundo os quais o bom enfrentamento pelo homem dos seus problemas lhe vale como uma importante função adaptativa, podemos supor, diante dos resultados desta pesquisa, que o vírus HIV impõe aos seus portadores uma condição à qual eles dificilmente se adaptam. Nessa mesma linha de argumentação, Flaskerud (1992) afirma que o tipo de reação da pessoa ao vírus HIV indica sua (in)capacidade de luta contra o mesmo, sendo visivelmente mais forte aquele que consegue exercer suas atividades normais, apesar da existência do vírus em seu organismo, e inevitavelmente mais fraco e passivo aquele se deixa levar pela progressão inexorável da doença.

Tais reações positivas e negativas parecem, de fato, estar associadas ao padrão atribuicional interno ou externo utilizado para explicar a contaminação pelo HIV. No caso do coping negativo, pode-se supor, por exemplo, que os pacientes, ao imputarem a responsabilidade pela contração do vírus a fatores externos, não vivenciam a culpa de tê-lo contraído e nem de terem contribuído para isso com seus próprios atos. A questão é suficientemente negada para que ele precise reagir ao vírus, configurando-se, assim, respostas de fuga e de passividade diante do mal que o acomete.

Quanto ao posicionamento dos atores e observadores em relação à crença em um mundo justo, os resultados obtidos apoiaram a idéia de que os portadores de HIV/AIDS tenderiam a possuir maior crença no mundo injusto ao passo que os observadores tenderiam a acreditar mais na justiça do mundo (hipótese H-5). Montada (1991) assinala que os observadores tendem a julgar mais justa que o próprio vitimado a situação de uma vítima de evento acidental devido a sua dificuldade de atribuir as causas do acidente a fatores de ordem ambiental. Como bem observam Dela Coleta (1982) e Furnhan e Procter (1989), não é cognitivamente possível para o homem aceitar condições de vida ruins, impostas por um acidente, se ele é um sujeito bom. Além disso, quando o observador imputa as causas de um acidente ao meio externo, ele fica tão passível de sofrer um acidente quanto a vítima observada. Aceitar que um acidente é uma ocorrência do acaso anula a previsibilidade que o homem julga possuir sobre os eventos. Em contrapartida, os próprios vitimados tendem a apresentar menor crença no mundo justo devido à dificuldade de terem que admitir sua contribuição causal ao infortúnio que os acometeu (Dela Coleta, 1982). É mais fácil para eles se defenderem da idéia de que participaram, de alguma forma, de seu processo de vitimação. Por isso, a tendência mais provável é que percebam a situação acidental como injusta, quando, literalmente, assumem uma condição de vítima.

A articulação possível entre atribuições causais à AIDS e crenças no mundo justo, foi evidenciada tanto nos grupos de observadores quanto nos de atores (hipótese H-6). Nesse sentido, os observadores, que responsabilizaram os portadores de HIV pelo contágio, e os atores, que se responsabilizaram pela aquisição do vírus, apresentaram maior crença no mundo justo e, inversamente, os atores e observadores, que fizeram atribuições externas à AIDS apresentaram maior crença no mundo injusto. Tomando por base tais achados, podemos supor que as pessoas estão sempre buscando uma lógica causal para as ocorrências do mundo, as que lhes acontecem e as que observam, e que, para isso, elas comumente precisam estabelecer uma correspondência entre ações praticadas e ganhos ou perdas recebidas, principalmente quando estão diante de um evento acidental (Dela Coleta, 1982). Assim, como os observadores não percebem aleatoriedade no contágio dos soropositivos, eles fazem atribuição causal interna aos atores e percebem justiça na sua soroconversão, o que, de certa forma, estabelece um relativo equilíbrio entre a situação vivida pelo doente e seus comportamentos anteriores. Já os atores, por não conseguirem, em boa parte, responsabilizar-se pela contração do HIV (o que baixaria em muito sua auto-estima), fazem mais atribuições externas à aquisição do vírus e tendem a perceber o evento vitimador da AIDS como injusto (Montada, 1991).

O contato direto com pessoas vivendo com AIDS, durante a coleta de dados desta pesquisa, nos permitiu ver sua rotina de perto e avaliar o quanto as dificuldades impostas por ela e suas experiências pós-diagnóstico são vivenciadas como injustas. São problemas freqüentemente observados no dia-a-dia dos soropositivos: a busca incessante de remédios (que, às vezes, faltam nos postos de saúde) e sua ingestão durante todo o dia (o que é conflitante para as pessoas que mantêm a soropositividade em segredo); a sustentação de uma dieta hiper-calórica recomendada para a manutenção do peso quando não dispõem de dinheiro para provê-la; as tentativas, às vezes infrutíferas, de manutenção do emprego, da vida afetiva e das amizades. Todas essas questões tornam-se para muitos portadores motivo de estagnação, o que não significa dizer, porém, que todos os soropositivos de que se têm notícias são ou estão ociosos. Alguns chegam a se tornar mais produtivos como se isso os fizesse viver mais, ou aproveitar melhor o tempo que possuem.

Acreditamos que o estudo atribuicional, envolvendo portadores de HIV seja relevante para os profissionais que atuam com esses pacientes, viabilizando atendimento mais eficaz por parte de médicos e psicólogos. Com base nos resultados ora obtidos, novas contribuições podem ser acrescidas à sua prática, especialmente a possibilidade de melhor compreender as interpretações da doença pelos 
soropositivos, bem como seus sentimentos de solidão e exclusão (pela dificuldade de serem aceitos por outras pessoas), e de impotência e finitude diante do problema possuído. A partir da identificação do tipo atribuicional empregado pelo portador de HIV, torna-se possível uma intervenção orientada no sentido de despertar a consciência dos portadores quanto a sua própria responsabilidade pela contaminação, seja por ação, seja por omissão. Por outro lado, o auto-exame das condições provocadoras da doença pode levar o paciente a internalizar a origem de seu problema e daí em diante desenvolver boas respostas de combate, que possam ser úteis ao controle da proliferação do vírus e que, certamente, tornarão a vida de seus portadores mais saudável. Além disso, os conhecimentos sociopsicológicos aqui discutidos, ao permitirem melhor compreensão da dinâmica interacional que envolve portadores de HIV, familiares, amigos e profissionais que lidam com eles, constituem valioso material de apoio à atuação desses profissionais da saúde, com vistas à melhoria na qualidade dessas relações, comumente tão conturbadas.

\section{Referências}

Anderson, V. N. (1992). For whom is this world just? Sexual orientation and AIDS. Journal of Applied Social Psychology, 22(3), 248-259.

Aronson, E., Wilson, T. D., \& Akert, R. M. (1997). Social psychology. Nova York: Addison-Wesley.

Bernstein, D. A., Roy, E. J., \& Wickens, C. D. (1997) Psychology. Boston: Houghton Miffin.

Dela Coleta, J. A. (1980). Atribuição de causalidade em presos, cegos e amputados: aceitação e luta contra o infortúnio. Tese de doutorado não-publicada, Fundação Getúlio Vargas, Rio de Janeiro.

Dela Coleta, J. A. (1982). Atribuição de causalidade: teoria e pesquisa. Rio de Janeiro: Fundação Getúlio Vargas.

Flaskerud, J. H. (1992). Infecção pelo HIV. Rio de Janeiro: Editora Médica e Científica/MEDSI.

Furnham, A., \& Procter, E. (1989) Belief in a just world: review and critique of the individual difference literature. British Journal of Social Psychology, 28, 365-384.

Heider, F. (1970). Psicologia das relações interpessoais (D. M. Leite, Trad.). São Paulo: Pioneira. (Original publicado em 1958)

Iório, A. C. R. (1996). Atribuição de causalidade à AIDS na perspectiva atorobservador. Dissertação de Mestrado não-publicada, Universidade Gama Filho, Rio de Janeiro.
Iório, A. C. R., Ferreira, M. C., \& Regato, V. C. (1996). Atribuição de causalidade em aidéticos na perspectiva ator-observador. Mente Social, 2(3), 19-26.

Jones, E. E., \& Davis, K. E. (1965). From acts to dispositions: the attribuition process in person perception. In Berkowitz, L. (Org.), Advances in Experimental Social Psychology (Vol. 2, pp. 219-266). Nova York: Academic.

Jones, E. E., \& Nisbett, E. R. (1972). The actor and the observer: divergent perceptions of the causes of behavior. In E. E. Jones, D. E. Kanause, H. H. Kelley, R. E. Nisbett, S. Alins, \& G. D. Weiner (Orgs.), Attribution: perceiving causes of behavior (pp. 79-94). Morristown, New Jersey: General Learning.

Lent, C., \& Valle, A. (1997). AIDS, sujeito e comunidade. Rio de Janeiro: Programa Nacional de DST/AIDS.

Lerner, M. J. (1975). The justice motive in social behavior: introduction. Journal of Social Issues, 31(3), 1-19.

Lerner, M. J. (1991). Integrating societal and psychological rules of entitlement: the basic task of each social actor and fundamental problem for the social sciences. In R. Vermunt \& H. Steensma (Orgs.), Social justice in human relations (Vol. 1, pp. 13-32). Nova York: Plenum.

Montada. L. (1991). Coping with life stress. Injustice and the question "Who is responsible?” In H. Steensma \& R. Vermunt (Orgs.), Social justice in human relations (Vol. 2, pp. 9-30). Nova York: Plenum.

Moulton, J. M., Swett, D. M., Temoshok, L., \& Mandel, J. S. (1987) Attributions of blame and responsibility in relation to distress and health behavior change in people with AIDS and AIDS-related complex. Journal of Applied Social Psychology, 17(5), 493-506.

Parker, R., Bastos, C., Galvão, J., \& Pedrosa, J. S. (1994). A AIDS no Brasil. Rio de Janeiro: Relume Dumará.

Ramos, H., Hinrichsen, S. L., Corrêa, P. R., Sá, P. V., \& Toscano, A. C. (1997) Infecção pelo HTLV-I/II. Revista ARS CVRANDI, 30, 54 -57.

Rublin, N. Z., \& Peplau, L. A. (1975). Who believes in a just world? Journal of Social Issues, 31(3), 65-87.

Santrok, J. W. (1997). Psychology. Madison, Winsconsin: Brown \& Benchmark.

Shaver, K. G. (1970). Defensive attribution: effects of severity and relevance on the responsibility assigned for an accident. Journal of Personality and Social Psychology, 14(2), 101-103.

Shaver, K. G. (1985). The attribution of blame: causality, responsibility and blameworthiness. Nova York: Springer-Verlag.

Sheehan, E. P., Lennon, R., \& McDevitt, T. (1987). Reactions to AIDS and other illness: reported interactions in the workplace. The Journal of Psychology, 123(6), 525-536.

Weiner, B. (1986). An attributional theory of motivation and emotion. Nova York: Springer-Verlag.

Weiner, B. (1995). Judgments of responsibility: a foundation for a theory of social conduct. Nova York: Guilford.

Weiss, J. J. (1997). Psychoterapy with HIV-positive gay men: a psychodynamic perspective. Publication of Institute for Biopsychosocial Medicine, 51(1), 31-34.

Vilma Cardoso Regato, mestre em Psicologia Social pela Universidade Gama Filho, é psicóloga clínica, e professora no Departamento de Ciências Sociais da Universidade Estácio de Sá. Endereço para correspondência: Av. Maracanã, 1302, ap.501, Rio de Janeiro, RJ; CEP 20.511-001. Tel.: (21) 2258-0498 e 9638-1010. Fax: (21) 2264-5813. E-mail: vilmaregato@terra.com.br

Eveline Maria Leal Assmar, doutora em Psicologia Social pela Universidade Federal do Rio de Janeiro, é pesquisadora do CNPq e professora titular no Programa de Pós-Graduação em Psicologia da Universidade Gama Filho. 